\title{
Commencing a nurse education role development journey in a regional Australian health district: Results from a mixed method baseline inquiry
}

\author{
Greg Fairbrother ${ }^{* 1,2}$, Rae Rafferty ${ }^{1,2}$, Andrew Woods ${ }^{1}$, Vanessa Tyler ${ }^{3}$, Wendy Howell ${ }^{4}$ \\ ${ }^{1}$ School of Health and Human Sciences, Southern Cross University, Lismore, NSW, Australia \\ ${ }^{2}$ Northern New South Wales Local Health District, Lismore, NSW, Australia \\ ${ }^{3}$ Lismore Base Hospital, Northern New South Wales Local Health District, Lismore, NSW, Australia \\ ${ }^{4}$ The Tweed Hospital, Northern New South Wales Local Health District, Tweed Heads, NSW, Australia
}

Received: March 9, 2015

DOI: $10.5430 /$ jnep.v5n8p7
Accepted: April 22, 2015

Online Published: May 13, 2015

URL: http://dx.doi.org/10.5430/jnep.v5n8p7

\begin{abstract}
Background: Health service-based nurse education roles (NERs) are well positioned to support the integration of theory and practice in Australian nursing. Despite this they are widely viewed as both poorly described and undervalued. Objective: To establish role parameters, typical activity profiles and views and attitudes about their roles, professional practices \& linkages, among a sample of regional Australian nurses in NERs.

Methods: Design: Participatory action research baseline inquiry. Participants: Nurse educators (NEs) and clinical nurse educators (CNEs) of the Northern New South Wales Local Health District. Mixed method baseline survey ( $\mathrm{n}=38,84 \%$ response rate) and focus group study (3 groups, $\mathrm{n}=33$ participants in total).

Results: Most survey participants were active in writing education programme material for Registered Nurses (RNs). Two thirds of survey respondents reported responsibility for medical staff training. CNEs were called upon to provide clinical relief (prompted by high patient acuity, sick leave and meal breaks) to the wards and units significantly more frequently than NEs. Activity logging indicated wide-ranging role domain diversity. Providing education and supporting clinical staff were the most prominent role domains for both NEs and CNEs. Dissatisfaction with aspects of NER was high - no role domain attracted higher than $60 \%$ overall satisfaction from this representative sample. Most participants were not research-active and many indicated the need for improvements in their linkages to the nursing academy. Focus group discussion suggested a group who were spread thinly, answerable to multiple governance tiers and intellectually under-supported. No consistent guiding educational philosophy was discernible in relation to participants' own teaching activity.

Conclusions: Principle issues related to the diversity of operational and professional responsibility tied to multiple impacting governance structures. Stable and purposeful linkages to nursing faculties/academia were also lacking.
\end{abstract}

Key Words: Teaching, Nurses, Nursing Education, Learning

\section{INTRODUCTION}

Unlike in the United Kingdom and the United States, where nursing education roles (NERs) often span both the academy and service environments, in Australia, along with New Zealand and Canada, they are generally service-based and funded. These clinically-based educators are thought to pro-

\footnotetext{
*Correspondence: Greg Fairbrother; Email: greg.fairbrother@scu.edu.au; Address: School of Health and Human Sciences, Southern Cross
} University and Northern New South Wales Local Health District, Lismore, NSW, Australia. 
vide an important role in facilitating the orientation, learning and practice development of a range of nursing and other health professional students and staff in clinical settings. The need for hospital-based professional NERs is fundamentally agreed to by both contemporary commentary ${ }^{[1,2]}$ and New South Wales Health strategy. ${ }^{[3]}$ Despite this, there appears to be agreement that NERs are both poorly described ${ }^{[1]}$ and likely to be undervalued. ${ }^{[2]}$ In response to this situation in the Northern New South Wales Local Health District (NNSW LHD) in 2013, nurses in NERs decided to commence an action research project aimed at scoping their roles and developing strategic directions. The NNSW LHD is a $20,732 \mathrm{~km}^{2}$ regional Australian health district serving a population of approximately 290,000 people, comprising 11 non-metropolitan, rural hospitals and community-based services and employing about 2,000 nurses and midwives. ${ }^{[4]}$

\subsection{Background}

Australian NERs are regularly positioned as key to the integration of theory and practice. Role domains identified include: facilitation of professional education, facilitation of nursing practice, providing nursing student support, and facilitating organisational goals. ${ }^{[5]}$ These role domains are however broad and potentially inclusive of many clinical, administrative and organisational foci. NERs may take responsibility for organisation-wide programs, in which case they may be likely designated a Nurse Educator (NE), or they may take responsibility for specialty specific programmatic activity, in which case they may be likely designated a Clinical Nurse Educator (CNE). There are no fixed rules and it is generally agreed that both $\mathrm{NE}$ and $\mathrm{CNE}$ roles are varied and complex. $^{[1,6]}$ The lack of clarity implicit in Australian NERs is likely to adversely impact on their localised enactment. North American and British writers have also described a lack of NER role clarity. ${ }^{[7,8]}$

Health systems are dynamic and complex, driven sociopolitically as well as scientifically, and the levers in play are funding-, policy- and regulation-related, to name a few. Unsurprisingly this dynamism drives unceasing role development, differentiation and diversity in service provision. At the practice-knowledge nexus, NERs are perhaps vulnerable more than most to pressurised and crisis-driven change, which may be developmental or regressive, depending on multiple factors. An example of system-sourced role pressure on NERs is the expansion in the scope of practice of the enrolled nurse (EN) role. ${ }^{[9]}$ Role scope changes require integration with the current nursing workforce as well as significant supervision, and NERs have an important part to play in all of this.

Recently, there has been an identified disconnect between
NER competency standards and actual practice and skill levels. ${ }^{[1,10,11]}$ Sayers (2013) studied the practice priorities and values of clinically based Australian NERs. Participants reported minimal involvement in the design and delivery of tertiary education. Research and partnership with academic colleagues were not prioritised as highly as other tasks. Despite this, participants reported that they valued knowledge and expertise developed through formal completion of study in education. ${ }^{[12]}$

\subsubsection{Certification and competency}

There is very little Australian publishing relating to certification and skillset requirements for NERs, though it has in the past been asserted that the provision of clinical nurse education in Australia is not possible without a supernumerary person with skills and knowledge of both education and clinical practice. ${ }^{[13]}$ At present there is no national standardised approach to role description and scope of practice in nurse education in Australia. ${ }^{[2,10]}$ There is no agreed formal qualification required for an Australian CNE role. The majority of NEs have an education qualification, however this ranges from a Certificate IV (below Bachelor level) to Masters (clinical or educational) level. ${ }^{[12]}$

The fundamental importance of a trained nurse education workforce has been emphasised in the United States. ${ }^{[14]}$ The importance of certification of NERs has also been stressed, in order for them to establish a speciality area, demonstrate expertise and communicate practice excellence. ${ }^{[15]}$ Despite this assertion, clarity in relation to certifying United States NERs only partly exists. Billings (2003) opines that although educational qualifications are required in American NERs, these vary and role statements don't always include what educators do. ${ }^{[7]}$ Available British/Irish writing suggests that emphasis has been placed in recent years on the maintenance of clinical currency among NERs. ${ }^{[16]}$ Gillespie \& McFetridge (2006) stress clinical credibility as a fundamental underpin to NER practice. ${ }^{[17]}$ Pollard et al. (2006) call for the achievement of professional teaching qualifications for all CNEs. ${ }^{[8]}$ There is a paucity of Canadian literature describing competencies for NERs. ${ }^{[18]}$ Preparation and support for CNE roles in New Zealand has also been found to be sub-optimal. ${ }^{[19]}$

In North America, graduate nurse education programs have been developed to provide certification and facilitate transition to NERs. ${ }^{[20]}$ These programs are however designed for academic roles and supervision of student clinical placements, as opposed to health service sector-based NERs.

The only organisation within Australia that has provided competencies explicitly for clinically-based NERs is the Australian Nurse Teacher's Society (ANTS). These professional practice standards include a core role of facilitating learning 
inclusive of designing effective teaching strategies as well as a commitment to research and scholarship activities.

\subsubsection{Patient outcomes}

A literature review exploring the relationships between NERs and patient outcomes located little evidence. ${ }^{[8]}$ Sayers \& DiGiacomo (2010) called for research to identify this relationship to enhance role sustainability and recognition for NERs as strategic stakeholders in the Australian Health Care System. ${ }^{[10]}$ Whilst there are some studies which point to the relationship between having a well-educated nursing workforce and lower patient mortality, ${ }^{[21-23]}$ these studies assessed formal qualification levels among nursing staff, rather than the presence of a ward-based NER.

In one large Australian mixed method study (10,000 patient records), data was examined to explore relationships between nurse staffing, workload, working environment and patient outcomes. ${ }^{[2]}$ The presence of a NER was associated with fewer medication errors, falls and adverse patient outcomes. ${ }^{[24]}$ Exploring exactly what these NERs did and how they did it, was not the purpose of that study. A recent United Kingdom systematic review regarding educational interventions in nursing concluded that interventions by educators to develop nursing judgement and decision-making are effective only some of the time and only in some circumstances. ${ }^{[25]} \mathrm{A}$ relative absence of robust, quality evaluations was reported. Milner et al. (2006) reviewed the nursing education literature specifically in relation to research utilisation and found only weak study designs. They recommended that future research on NERs should prioritise the outcomes of research utilisation and the effectiveness of NERs as facilitators. ${ }^{[26]}$

\subsection{Aims}

In order to inform ongoing participatory action research (PAR) activity in relation to NERs in the NNSW LHD, to establish at baseline: i) role parameters of NERs; ii) typical activity profiles of NERs; iii) the views and attitudes of those occupying NERs, about their roles, needs, professional practices and linkages. This information is important for a PAR project which seeks to drive NER role development, as a shared understanding of current role functions, aspects and experiences is needed among both project team members and stakeholders. Shared understandings are assistive to the ongoing reflection and collective inquiry and development process.

\section{METHOD}

A PAR project was commenced among NEs and CNEs of the health district in 2013. This project is ongoing. The principle aims are to develop and progress a clear structure and function for the LHD's NERs. The data reported here relates to the baseline studies conducted in the opening PAR cycle.

PAR is an amalgam of research inquiry and practical change. It pursues action (usually change or development) and research (or inquiry-based understanding) at the same time. A cyclic process which alternates between action and critical reflection is often used. Inquiry methods and change processes remain un-cemented and may alter as the spiral of action and reflection builds towards the agreed goal. Its participative nature requires a referent group made up of participants in the change process. ${ }^{[27]}$ PAR has been used in different ways in nursing, and with varying results. PAR studies aimed at changing working conditions for nurses have been reported, as have studies on new nursing practice initiatives and nurse empowerment. ${ }^{[28-30]}$

The first cycle of inquiry and reflection in the PAR process is important as it is baseline-generating and informs opening changes. Two forms of initial inquiry were employed in this project. Firstly, a survey of NEs and CNEs was conducted. Consecutive sampling was employed - all NEs $(n=11)$ and CNEs $(n=34)$ of the health district were targeted. Key response domains canvassed by the survey were: demographics, role activity, role satisfaction and expressed needs. The survey instrument was designed by the PAR project team. In line with the goals of the project, much of the questioning was descriptive and/or pragmatic in nature. For this reason psychometric measurement was not undertaken. Activity profile and role satisfaction were cross-sectionally assessed using chi-square or one-way analysis of variance (ANOVA) analysis, against position category (NE or CNE) of respondent. The baseline survey was distributed in both online and hardcopy format, to allow for maximum opportunity for participants to respond. Resultant responses were analysed using SPSS v20. ${ }^{[31]}$ Following the survey, three focus group discussions ( $n=10, n=10$ and $n=13)$, were held to discuss the survey results. Open-ended survey responses and focus group discussion transcripts were subject to thematic content analysis. Study group members conducted content analysis separately. Final thematic analyses were then generated in group analysis sessions attended by the entire research group. Videoconferencing allowed for the participation of those unable to physically attend. Both survey and focus group inquiries were approved by the North Coast NSW Human Research Ethics Committee.

\section{RESULTS}

\subsection{Survey response}

Eleven (100\%) NEs and 27 (79\%) CNEs responded, yielding a total sample size of $n=38$ and overall response rate of $84 \%$. 


\subsection{Survey respondent demographics}

Respondent demographics are summarised in Table 1 . The data indicate a mature and experienced population of nurses and midwives who were often working part-time. Differences between NEs and CNEs on the demographics were non-significant.

Table 1. Survey respondent demographics $(\mathrm{n}=38)$

\begin{tabular}{|c|c|c|c|}
\hline Demographic & Category & n & $\%$ \\
\hline \multirow{5}{*}{ Age range (years) } & $31-40$ & 9 & 23 \\
\hline & $41-50$ & 12 & 30 \\
\hline & $51-60$ & 7 & 18 \\
\hline & $>60$ & 2 & 8 \\
\hline & Not stated & 8 & 21 \\
\hline \multirow{4}{*}{ Employment status } & Substantive position ${ }^{\#}$ & 30 & 79 \\
\hline & Full-time & 15 & 40 \\
\hline & Part-time & 19 & 50 \\
\hline & Temporary & 4 & 10 \\
\hline \multirow{5}{*}{ Years in nursing } & $10-20$ & 12 & 32 \\
\hline & $21-30$ & 8 & 21 \\
\hline & $31-40$ & 5 & 13 \\
\hline & $>40$ & 4 & 11 \\
\hline & Not stated & 9 & 23 \\
\hline \multirow{5}{*}{ Years in an education role } & $<1$ & 4 & 10 \\
\hline & $1-5$ & 10 & 26 \\
\hline & $6-10$ & 11 & 29 \\
\hline & $>10$ & 4 & 10 \\
\hline & Not stated & 9 & 24 \\
\hline
\end{tabular}

${ }^{\#}$ Denotes a permanent position which is fully funded

3.3 Activity: Education program development and oversight

Figure 1 outlines survey participants' self-reported education program development activity. Results indicate that most survey participants were active in writing education programme material for Registered Nurses (RNs). Preparation of programme material for Enrolled Nurses (ENs) was done more often by NEs than CNEs $\left(\chi^{2}=8.5, P=.004\right)$.

Respondents were asked to indicate level of involvement in overseeing transition to practice programs for new graduate RNs and ENs. Sixty six percent $(66 \% ; n=25)$ of respondents were involved in RN transition, whilst only $21 \%(\mathrm{n}=$ 8) were involved in EN transition. In Australia, ENs occupy a position lower on the clinical ladder than RNs, and are usually not degree qualified. Respondents were also questioned regarding specialty area-specific transition. A marked difference $\left(\chi^{2}=6.7 ; P=.01\right)$ was noted between NEs and CNEs regarding this: $73 \%$ of CNEs $(n=20)$ were involved, versus $22 \%$ of NEs $(n=2)$.

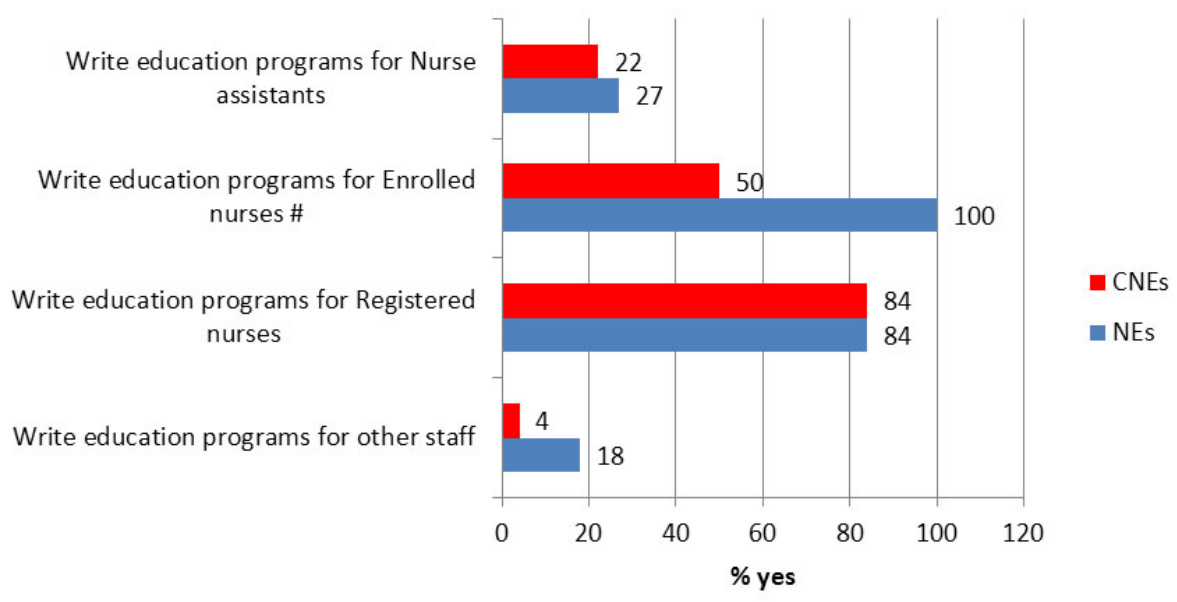

Figure 1. Education program development activity \# Significant difference $(P<.05)$ between NEs and CNEs 


\subsection{Activity: Professional}

$\mathrm{NE}$ and CNE involvement in professional and other educational activity is summarised in Figure 2. Two thirds of respondents $(n=25)$ reported responsibility for medical staff training and $42 \%(n=16)$ reported responsibility for allied health staff training.

NEs were more likely to focus on the development of prac- tice competency guidelines than CNEs (100\% vs $56 \% ; \chi^{2}$ $=7.1, P=.008)$ and also more likely to be involved in the planning and delivery of larger educational initiatives (64\% vs $\left.33 \% ; \chi^{2}=2.9, P=.08\right)$. CNEs were more likely than NEs to be involved in staff mandatory training $\left(82 \%\right.$ vs. $36 \% ; \chi^{2}$ $=7.4, P=.007)$. Involvement in research was low among both groups.

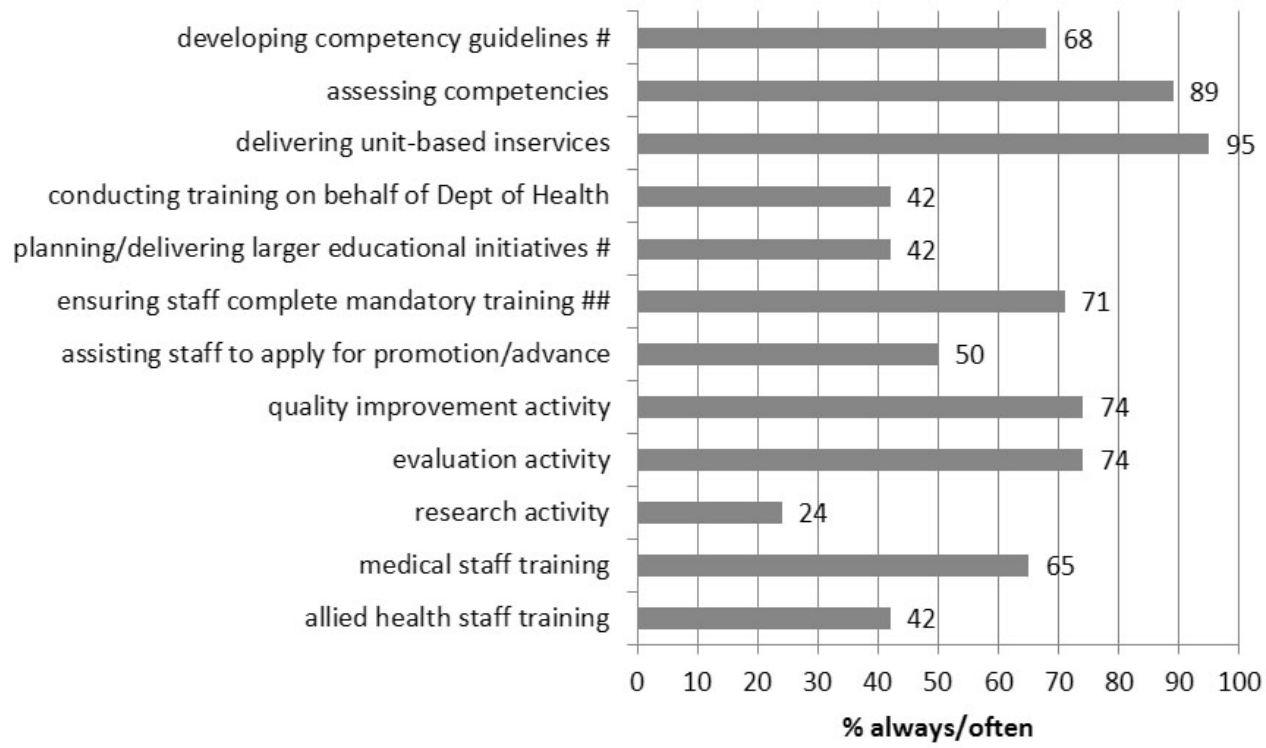

Figure 2. Professional \& other educational activity \# Significant difference $(P<.05)$ between NEs and CNEs in the direction of greater NE involvement; \#\# Significant difference $(P<.05)$ between NEs and CNEs in the direction of greater CNE involvement

\subsection{Activity: Relieving}

Figure 3 outlines how much clinical relief NEs and CNEs were providing, prompted by high patient acuity, sick leave and meal cover. CNEs were called upon more than NEs in this regard (meal break relief: $\chi^{2}=5.3, P=.02$; clinical relief [high acuity] $\left.\chi^{2}=6.9, P=.009\right)$. More than $50 \%$ of CNEs $(n=14)$ indicated that they did clinical or meal break relief daily/second daily. Many CNEs indicated that the unpredictable nature and level of relief was hard to sustain whilst doing justice to their planned activities.

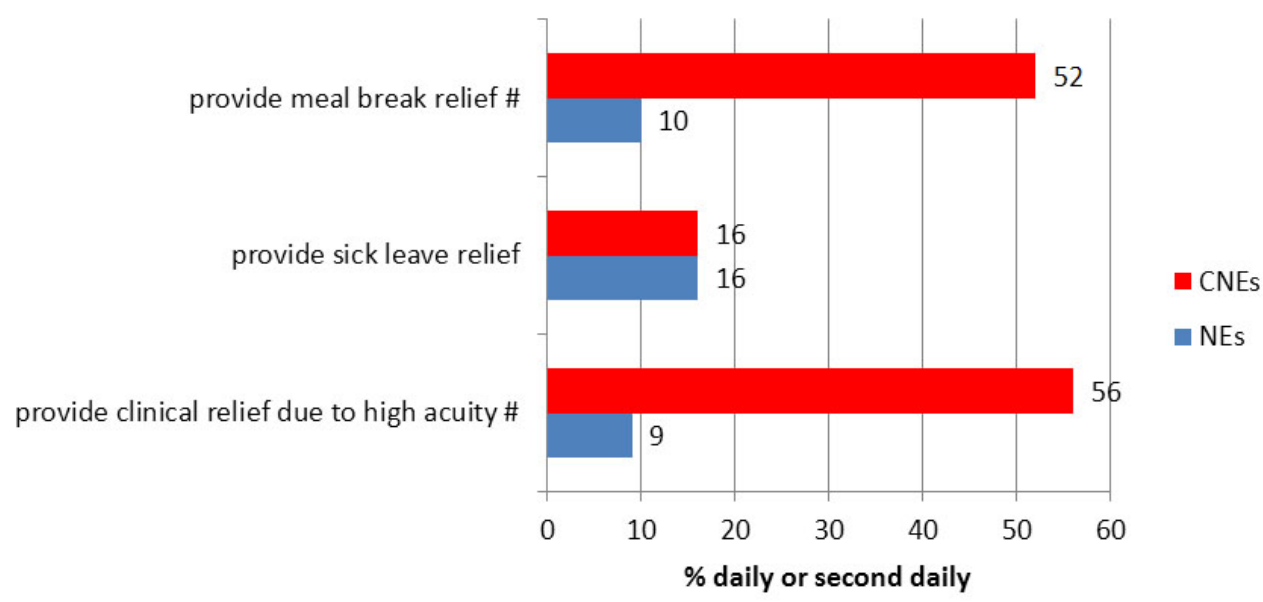

Figure 3. Relieving others

\# Significant difference $(P<.05)$ between $N E s$ and $C N E S$ 


\subsection{Focus group discussion: Education program and professional activity}

Discussion regarding professional domain based activity indicated that participants were unsurprised by the high number who reported doing medical staff training. It was agreed that this work is not in NE/CNE role statements and that the roles aren't funded to conduct it. However, many characterised their roles as being viewed as "on the floor" subject matter experts. So, when the need arises to do medical staff training, they may not demur, as they know the education is needed for patient safety, and that there's no one else to do it. It was asserted by some that there exists a danger of losing interdisciplinary communication channels if educators were to refuse to do this work. Discussion also suggested that significant time is spent on directing medical officers to appropriate guideline and policy material. It was widely agreed that the formal structure for training medical students was inadequate to the task. All indicated a desire to see this issue addressed structurally. More than one participant queried why part of the medical education budget isn't allocated to nursing.

A preferred move from specialty-defined clinical programbased governance towards centralised governance of NERs was raised in the context of the medical education situation:

"If we had a more formal governance structure, when something new came out ... it wouldn't fall to the nurses to educate the doctors on it. There's no benefit for our nurses by spending 20 hours convincing doctors to use a new chart or process that the Health Department says we have to use anyway. If we had a structure, it could go straight over to the Medical Services people and down that way, instead of going down our way, because it's the only way for it to go at the moment." (Participant, Focus group 1)

NE/CNE responsibility for tracking, organising and clinically relieving staff to attend or run, mandatory training, was discussed as an area of dissatisfaction. Some felt that responsibility for mandatory training should lie with the unit manager. Regardless, a more organised structure for NERs was seen to likely help with managing individual loads here:

"I'm not sure that doing basic life support for domestic staff should be in my role." (Participant , Focus group 3)

All participants felt that bedside teaching of nurses was of fundamental role importance and were frustrated that they were not always in a position to do this to the level they would like.

\subsection{Activity: Typical overall profile}

Respondents were asked to complete an activity log in real time over a two week period. A range of activity areas were proposed. Respondents were also asked to rate their satisfaction with the amount of time devoted to the activity domains logged. Analysis of this material is summarised in Figures 4 and 5.

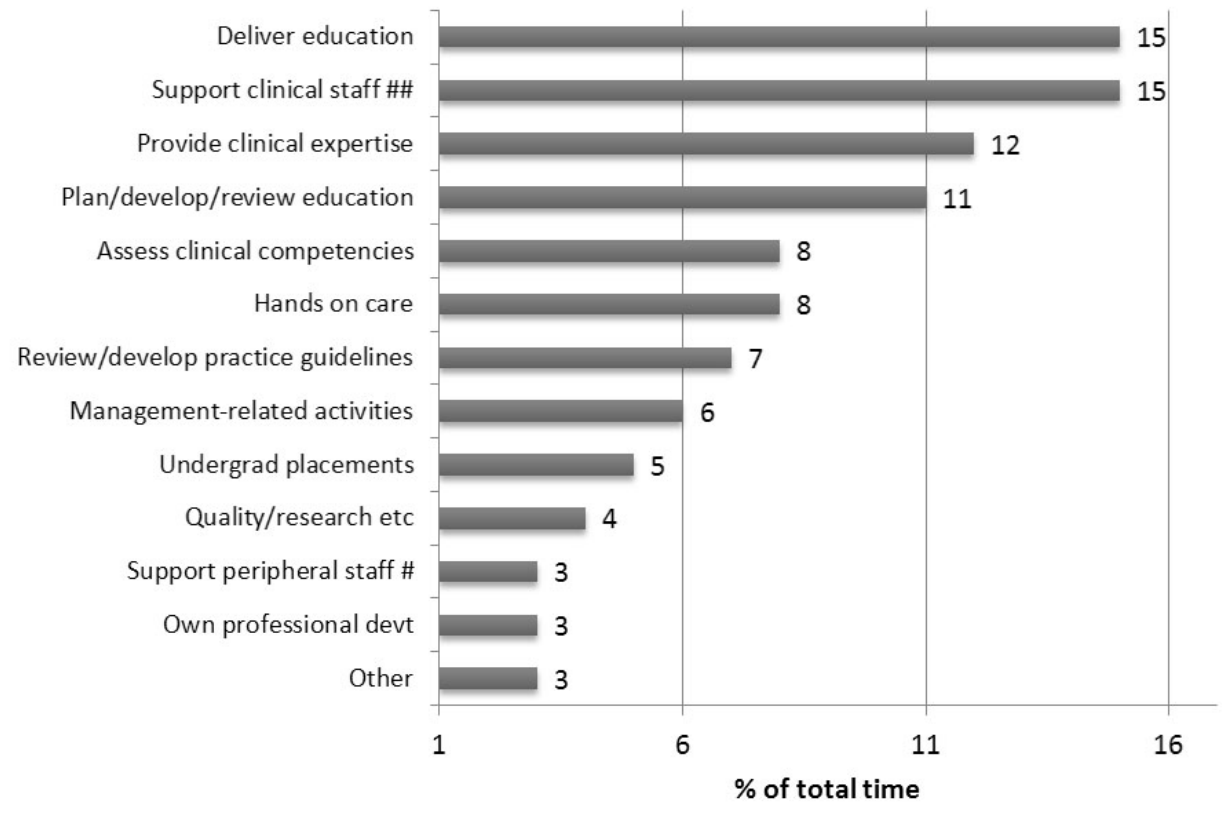

Figure 4. Typical NE/CNE activity profile

\# Significant difference $(P<0.05)$ between NEs and CNEs in the direction of greater NE involvement; \#\# Significant difference $(P<0.05)$ between NEs and CNEs in the direction of greater CNE involvement. 
Figure 4 illustrates an equivocal typical activity profile between the two principal NERs (NEs and CNEs), with two marked differences - support of clinical staff was significantly (twice) more prominent for CNEs $(\mathrm{F}=5.1 ; P=.03)$ and support of peripheral staff was significantly (thrice) more prominent for NEs $(\mathrm{F}=7.4 ; P=.01)$. Figure 5 suggests a NER workgroup that has areas of real dissatisfaction. No role domain attracted above $60 \%$ satisfaction. Where satisfaction differences occurred by role, they were in the direction of greater dissatisfaction among CNEs (Delivery of clinical education: NE satisfaction $75 \%$, CNE satisfaction $35 \%: \chi^{2}$ $=3.7, P=.05$. Assessment of clinical competency: NE satisfaction $75 \%$, CNE satisfaction $32 \%: \chi^{2}=4.3, P=.04$ ).

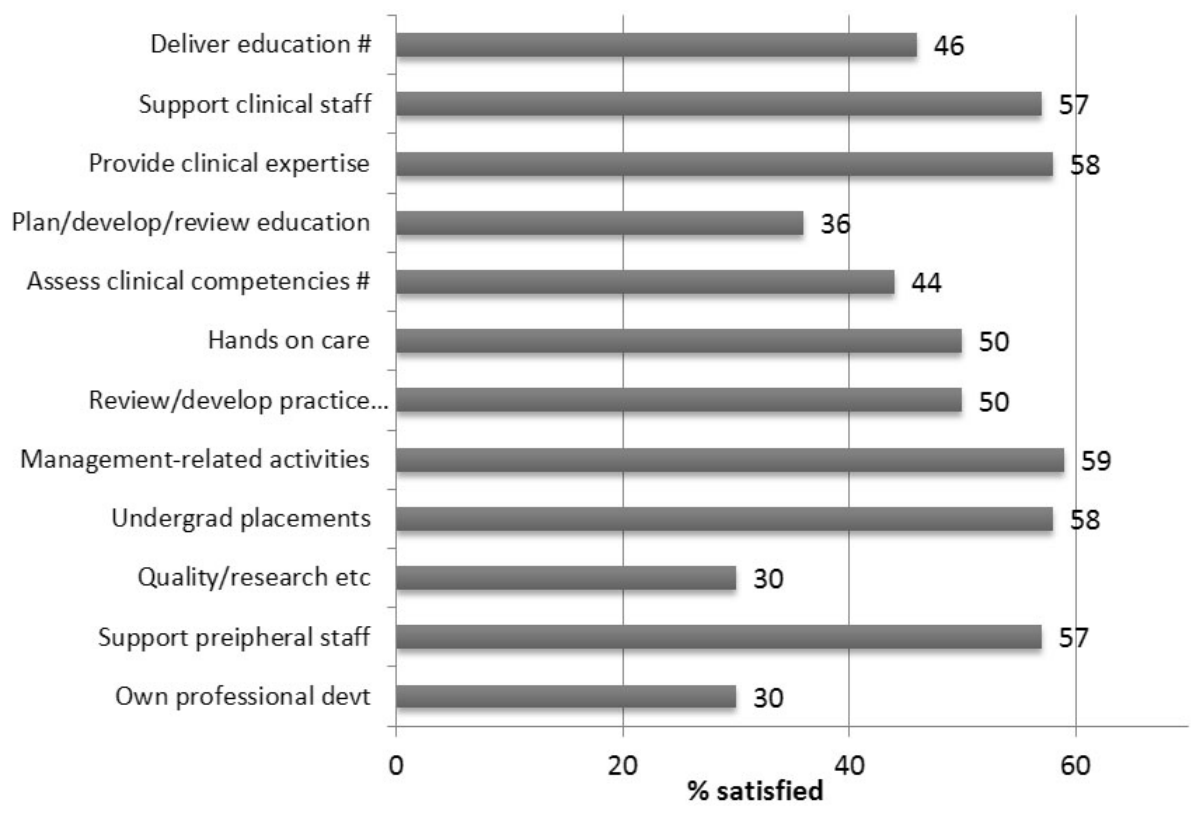

Figure 5. Proportion of NEs/CNEs satisfied with typical activity

\# Significant difference $(P<.05)$ between NEs and CNEs in the direction of greater NE satisfaction

\subsection{Focus group discussion: Typical overall activity}

Participants noted duplication and limited communication across the various regionally-defined levels of the health district. A result of this was a lack of standardised learning packages and practice guidelines. All agreed that there was often confusion distinguishing the two NERs (NEs and CNEs). This was attributed to how the funding for the roles had been obtained, what the positions had been earmarked for politically, and the gradual adding on functions to each role. Historically CNEs were funded first, then NEs were employed in the more overarching roles. CNEs are allocated to departments largely but may also have facility-wide roles. It was agreed that CNEs (as the more frontline role) largely operated on the basis of short term need and that there is often a lack of clear guidance for them. Job descriptions were discussed as being in a state of flux. Participants spoke of collegial relationships with managers, but that multiple managerial relationships didn't help them get their jobs done. Centralised governance was again raised as a strategic option:

"I have multiple managers because of the different sites I work from. This means that there's too many fingers in the pie.” (Participant, Focus group 1)

"Central co-ordination could work ... if we could just all report to someone at a district level." (Participant, Focus group 2)

Some participants suggested that issues raised with regards medical staff training, mandatory training, duplication of work, succession planning, mentoring and clinical/leave relief might all be progressed more advantageously under a more centralised governance model.

\subsection{Expressed education needs}

Thirty two percent $(32 \% ; \mathrm{n}=12)$ of respondents held a Master's degree and $10 \%(n=4)$ were studying towards one. Fifty eight percent $(58 \% ; n=22)$ had a Certificate in Training and Assessment. Differences between NEs/CNEs, regarding qualifications were small. Respondents were asked their view regarding minimum/ideal qualification levels for NERs. Most supported Masters for NEs and Postgraduate Diploma for CNEs as minimum and ideal.

Respondents were asked to indicate their skill development needs. Content analysis indicated the following as most 
prominent: i) dealing with difficult staff; ii) coaching/ leadership; iii) simulation; iv) e-learning; v) clinical teaching. Additional needs noted by NEs related to strategic planning, doctorate level study and managing an ageing workforce. CNEs flagged mentoring, research, conflict resolution and team building.

Respondents were asked to indicate the educational philosophy that they draw from in relation to their own teaching activity. Some $40 \%$ of respondents $(n=16)$ did not provide a response to this. Among those who did, no common theme was evident. Responses varied considerably, ranging from "not sure" to "own clinical experience" through "health bureaucracy policy" to "humanistic theory".

Focus group discussion regarding the prominence of the Training Certificate as the "standard" educational preparation for NERs, indicated mixed views as to the usefulness of this. More theoretical content was viewed as necessary. Some felt that Masters level preparation was needed for all NERs, whilst others were less convinced. All viewed the prevailing certificate level preparation as inadequate. Participants were unsurprised by the diverse range of responses to the survey question on educational philosophy, and the absence of a clear philosophical "backdrop" to practice suggested by many responses. All agreed that there was a need for NERs to become more skilled at working with and translating education theory into practice and that a better training base would likely help.

\subsection{Tertiary relationships}

Fifty eight percent $(58 \% ; n=22)$ of respondents reported having active university partnerships. Some expressed a view that there was no need for tertiary partnerships, suggesting a window for greater tertiary/service level integration to occur. In discussion, participants expressed the view that some courses being run at service level should contribute to university credit points. All agreed that they don't have the time to write/work up subjects. Participants suggested that many service-sourced course hours could be converted to tertiary credits/hours, if faculties were to assist in developing this activity stream. The nursing academy was viewed as "not closing the loop" for NERs in this regard.

Focus group participants discussed what they feel makes a good relationship with a university partner. Communication and respect were raised. Participants often indicated that they had little knowledge of their local nursing academy:

"What I've seen elsewhere is that the uni will have convenors that work... that may have an office in the hospital, as well as the uni." (Participant, Focus group 1)

Participants suggested greater coordination between the two 14 sectors, with more involvement in each other's planning.

\section{Discussion AND CONCLUSION}

This opening survey and focus group inquiry among a population sample of regional Australian nurses in NERs, who are in the process of embarking on participatory role development activity, suggests an operational environment which is beset by numerous challenges.

A lack of formal pedagogical theory was evident with regards their varying experiences of preparation for their roles. The Certificate in Training and Assessment is clearly inadequate to its current task as the "standard" for NER preparation. This course is quasi-academic only and participants' insubstantial responses to the survey question about the theoretical position taken when planning and conducting education activity reflects this. This confused and inadequate certification scenario for NERs in Australia has been raised repeatedly in recent years. ${ }^{[2,12]}$ There is a need for postgraduate course development in nursing pedagogy in Australia to remedy this. If role preparation is in need of greater formal input from the nursing academy, these inquiry results suggest that role maintenance and everyday NER practice is also in need of a greater academic presence. Worrying numbers of participants were unaware and/or unconnected to the academy as a source of ongoing professional support. Results from activity logging indicate that research and quality assurance activity is a relatively minor component of the NERs. These results suggest a group who are intellectually isolated on a day to day basis and subject to multiple and ongoing organisationallydriven changes in role demands.

The service environment lacks expressed clarity as to where and how to position the NERs. Many participants were answering to multiple managerial lines and the activity log results indicate a wide ranging practice brief. Regularised NER involvement in medical, allied health and ancillary staff training was a source of dissatisfaction for some, though not all participants. The inadequacy of service-based medical training resources has been described before. ${ }^{[32]}$ Whether and how NERs continue in such activity into the future, clearly requires role funding base assessment at organisational level.

Role dissatisfaction was widespread. Less than half of respondents were satisfied with their role in education delivery and clinical competency assessment. More dissatisfaction existed among CNEs than NEs, perhaps reflecting the greater demands placed on this group to routinely abandon their planned activities altogether, in order to relieve.

Focus group discussion yielded an emergent consensus regarding the potential benefits of a more centralised structure for the NERs. This view seems unsurprising given the 
centripetal nature of the forces described by participants as impacting them.

Very few authors have reported using PAR as a change mechanism in the NER sector. ${ }^{[5]}$ McAllister (2012) proposed the use of action research to facilitate the formation of communities of practice amongst nurse educators. ${ }^{[11]}$ The potential benefits of such collaborative networks include role clarity, decreased isolation, sharing of finite resources, reduced duplication of work and support for ongoing professional development and mentorship. ${ }^{[33]}$ PAR has been used to develop collaborations amongst nurse practitioners ${ }^{[28]}$ with demonstrated positive outcomes regarding role clarity and integration, autonomy for role enactment, team capacity and strategic alliances.

A paradigm shift in nursing pedagogy may be required in or- der to achieve real change. Traditional models of instruction where learners are passive recipients of information need to cede ground to more critical models, where learners are engaged in the process of autonomy and empowerment. ${ }^{[34]}$ The baseline results described here position this regional Australian group of nurses and midwives well to begin the action cycles required by the PAR process and with the support of their managers and colleagues from both academic and service sectors, initiate meaningful and forward-directional change. It is likely that the establishment of nurse educationrelated communities of practice across the health district will form one plank of the role development bridge into the future which is being charted by this important group of nurses.

\section{Conflicts of InTEREST Disclosure}

The authors declare that there is no conflict of interest statement.

\section{REFERENCES}

[1] Sayers J, DiGiacomo M, Davidson P. The nurse educator role in the acute care setting in Australia: Important but poorly described. Australian Journal of Advanced Nursing. 2011; 28(4): 44-52.

[2] Sayers J. Survey reveals educators undervalued. Australian Nursing Journal. 2011; 18(2): 43.

[3] Australian Government National Health and Hospitals Reform Commission (AGNHHRC). A healthier future for all Australians: Final Report of the National Health and Hospitals Reform Commission. Canberra: Australian Government; 2009.

[4] New South Wales Health Ministry. Northern NSW Local Health District Strategic Plan 2012-2017 Sydney: NSW Health; 2012.

[5] Conway J, Elwin C. Mistaken, misshapen and mythical images of nurse education: Creating a shared identity for clinical nurse educator practice. Nurse Education in Practice. 2007; 7(3): 87194. PMid:17689443 http://dx.doi.org/10.1016/j.nepr. 20 06.08 .005

[6] Mateo M, Fahje C. The nurse educator role in the clinical setting. Journal for Nurses in Staff Development. 1998; 14(4): 169175. PMid:9807332 http: //dx . doi .org/10 . 1097/00124645-1 99807000-00001

[7] Billings D. What Does it Take to be a Nurse Educator? Journal of Nursing Education. 2003; 43(3): 99-100.

[8] Pollard C, Ellis L, Stringer E, et al. Clinical Education: A review of the literature. Nurse Education in Practice. 2006; 7: 315322. PMid:17689458 http://dx.doi.org/10.1016/j.nepr. 20 06.10 .001

[9] Rodney P, Burton A. It's time to Talk about CDMR. Association of Registered Nurse of British Columbia (ARNBC) Blog. 2014. Available from: http://www.arnbc.ca/blog/its-time-to-t alk-about-cdmr-by-paddy-rodney-rn-and-andrea-bur ton/

[10] Sayers J, DiGiacomo M. The nurse educator role in Australian Hospitals: Implications for Health Policy. Collegian. 2010; 17(2): 77-84. PMid:20738060 http://dx.doi.org/10.1016/j.coleg n.2010.04.005

Published by Sciedu Press
[11] McAllister M. Challenges facing nursing education in Australia: Two solutions. Journal of Nursing Education and Practice. 2012; 2(1): 2027. http://dx.doi.org/10.5430/jnep.v2n1p20

[12] Sayers J. The role of the nurse educator in acute care hospitals Australia. (Unpublished PhD thesis). Curtin University, Australia; 2013.

[13] Considine J, Hood K. A study of the effects of the appointment of a Clinical Nurse Educator in one Victorian Emergency department. Accident and Emergency Nursing. 2000; 8: 71-78. PMid:10818370 http://dx.doi.org/10.1054/aaen.1999.0100

[14] Nursing Executive Center. Customised Career Sculpting. Washington. The Advisory Board Company. 2008.

[15] Burton J. Certification of Nurse Educators. Med-Surg Matters. 2011; 20(5): 18 .

[16] Carr G. Changes in nurse education: Being a nurse teacher. Nurse Education Today. 2007; 27(8): 893-899. PMid:17321014 http: //dx.doi.org/10.1016/j.nedt.2006.12.006

[17] Gillespie M, McFetridge B. Nurse Education - the role of the nurse teacher. Journal of Clinical Nursing. 2006; 15: 639-644. PMid:16629973 http://dx.doi.org/10.1111/j.1365-2702. 2006.01344.x

[18] Young L, Frost L, Bigl J, et al. Nurse Educator Pathway Project: a competency-based intersectoral curriculum. International Journal of Nursing Education Scholarship. 2010; 7(1): 1. PMid:21126229 http://dx.doi.org/10.2202/1548-923X. 2082

[19] Manning L, Neville S. Work-role transition: from staff nurse to clinical nurse educator. Nursing Praxis in New Zealand. 2009; 25(2): 41-53. PMid:19928650

[20] Kalb K. Core competencies of nurse educators: Inspiring excellence in nurse educator practice. Nursing Education Perspectives. 2008; 29(4): 217-219. PMid:18770950

[21] Aiken L, Clarke S, Cheung R, et al. Educational levels of hospital nurses and surgical patient mortality. Journal of the American Medical Association. 2003; 290(12): 1617-1623. PMid:14506121 http://dx.doi.org/10.1001/jama.290.12.1617

[22] Estabrooks C, Midodzi W, Cummings G, et al. The impact of hospital nursing characteristics on 30 day mortality. Nursing Research. 2005; 
54(2): 74-84. http://dx.doi.org/10.1097/00006199-20050 3000-00002

[23] Tourangeau A, Doran D, McGillis HL, et al. Impact of hospital nursing care on 30-day mortality for acute medical patients. Journal of Advanced Nursing. 2007; 57: 32-44. PMid:17184372 http://dx.doi.org/10.1111/j.1365-2648.2006.04084.x

[24] Duffield C, Roche M, O'Brien-Pallas L, et al. Glueing it together: Nurses, their work environment and patient safety. 2007. Available from: http://www.health.nsw.gov.au/pubs/2007/pdf/ nwr_report.pdf

[25] Thompson C, Stapley S. Do educational interventions improve nurses' clinical decision making and judgment? A systematic review. International Journal of Nursing Studies. 2011; 48: 881893. PMid:21241984 http://dx.doi.org/10.1016/j.ijnurst u. 2010.12.005

[26] Milner M, Estabrooks A, Myrick F. Research utilization and clinical nurse educators: a systematic review. Journal of Evaluation in Clinical Practice. 2006; 12(6): 639-655. PMid:17100863 http: //dx.doi.org/10.1111/j.1365-2753.2006.00632.x

[27] Holter I, Schwartz-Barcott D. Action research: what is it? How has it been used and how can it be used in nursing? Journal of Advanced Nursing. 1993; 18(2): 298-304. http://dx.doi.org/10.1046/j .1365-2648.1993.18020298.x
[28] Burgess J, Purkis M. The power and politics of collaboration in nurse practitioner role development. Nursing Inquiry. 2010; 17(4): $297-$ 308. PMid:21059147 http://dx.doi.org/10.1111/j.1440-1 800.2010.00505.x

[29] Taylor B. Reflective Practice: A guide for nurses and midwives. Sydney: Allen \& Unwin; 2010.

[30] Waterman H. Embracing ambiguities and valuing ourselves: Issues of validity in action research. Journal of Advanced Nursing. 1998; 28: 101-105. http://dx.doi.org/10.1046/j.1365-2648.19 $98.00763 . \mathrm{x}$

[31] IBM. SPSS Statistics, Version 20. 2008.

[32] Stecketee C, Forman D, Dunston R, et al. Interprofessional health education in Australia: Three research projects informing curriculum renewal and development Applied Nursing Research. 2014; 27 : 115 20. PMid:24792131 http://dx.doi.org/10.1016/j .apnr. 20 14.03 .002

[33] Coates K, Fraser K. A case for collaborative networks for clinical nurse educators. Nurse Education Today. 2014; 34(1): 6-10. PMid:23628191

[34] Allen S. The revolution of nursing pedagogy: a transformational process. Teaching and Learning in Nursing. 2010; 5(1): 33-38. http: //dx.doi.org/10.1016/j.nedt.2013.04.003 